\title{
Fine Tuning of Reactive Oxygen Species Homeostasis Regulates Primed Immune Responses in Arabidopsis
}

\author{
Victoria Pastor, ${ }^{1}$ Estrella Luna, ${ }^{2}$ Jurriaan Ton, ${ }^{2}$ Miguel Cerezo, ${ }^{1}$ Pilar García-Agustín, ${ }^{1}$ and Victor Flors ${ }^{1}$ \\ ${ }^{1}$ Plant Physiology Section, Department of CAMN, Univesitat Jaume I, 12071, Castellón, Spain; ²Department of Animal and \\ Plant Sciences, Alfred Denny Building, The University of Sheffield, Sheffield, S10 2TN, U.K.
}

Submitted 23 April 2013. Accepted 4 July 2013.

\begin{abstract}
Selected stimuli can prime the plant immune system for a faster and stronger defense reaction to pathogen attack. Pretreatment of Arabidopsis with the chemical agent $\beta$ aminobutyric acid (BABA) augmented $\mathrm{H}_{2} \mathrm{O}_{2}$ and callose production after induction with the pathogen-associated molecular pattern (PAMP) chitosan, or inoculation with the necrotrophic fungus Plectosphaerella cucumerina. However, BABA failed to prime $\mathrm{H}_{2} \mathrm{O}_{2}$ and callose production after challenge with the bacterial PAMP Flg22. Analysis of Arabidopsis mutants in reactive oxygen species (ROS) production (rbohD) or ROS scavenging (pad2, vtc1, and cat2) suggested a regulatory role for ROS homeostasis in priming of chitosan- and $P$. cucumerina-inducible callose and ROS. Moreover, $r b o h D$ and $p a d 2$ were both impaired in BABA-induced resistance against $P$. cucumerina. Gene expression analysis revealed direct induction of $\mathrm{NADPH} / \mathrm{res}$ piratory burst oxidase protein $D(R B O H D), \gamma$-glutamylcysteine synthetase 1 (GSH1), and vitamin C defective 1 (VTC1) genes after BABA treatment. Conversely, ascorbate peroxidase 1 (APX1) transcription was repressed by BABA after challenge with chitosan or $P$. cucumerina, probably to provide a more oxidized environment in the cell and facilitate augmented ROS accumulation. Measuring ratios between reduced and oxidized glutathione confirmed that augmented defense expression in primed plants is associated with a more oxidized cellular status. Together, our data indicate that an altered ROS equilibrium is required for augmented defense expression in primed plants.
\end{abstract}

Throughout their life cycle, plants are constantly threatened by potentially harmful microbes. To cope with these threats, plants have evolved a sophisticated immune system that allows them to respond to invaders with inducible defense mechanisms. The speed and intensity by which these inducible defenses are activated largely determines the level of resistance expressed against plant attackers. Pattern-recognition receptors (PRR) allow plants to recognize pathogenic microbes at an early stage of infection, which detect pathogen-associated molecular patterns (PAMPs), microbe-associated molecular patterns (MAMPs), or damage-associated molecular patterns and activate innate immune responses, commonly referred to as PAMP-triggered immunity (PTI) (Boller and Felix 2009;

Corresponding author: V. Flors; E-mail: flors@uji.es

* The $\boldsymbol{e}$-Xtra logo stands for "electronic extra" and indicates that four supplementary figures and one supplementary table are published online and that Figure 5 appears in color online.

(C) 2013 The American Phytopathological Society
Gómez-Gómez and Boller 1999; Zipfel 2009). Among many other responses, PTI includes reactive oxygen species (ROS) production, activation of mitogen-activated protein kinase (MAPK) cascades, callose deposition, synthesis of secondary metabolites, and transcriptional reprogramming through WRKY transcription factors. A co-evolutionary arms race between plant pathogens and their hosts provided plants with an extension of their innate immune system, called effector-triggered immunity (ETI) (Bent and Mackey 2007; Jones and Dangl 2006). ETI allows plants to detect and respond to the attempt of the pathogens to suppress the host immune responses. Both PTI and ETI share partially similar signaling pathways, such as ROS production and changes in gene expression. However, the overarching factors determining efficiency of plant innate immune responses are speed and intensity relative to the colonization rate of a potential pathogen (Tsauda and Katagiri 2010).

In addition to innate immune responses, plants can also acquire a "sensitized defense state" in response to specific environmental stimuli. This so-called "priming of defense" is an important mechanism underpinning induced resistance (IR) in plants (Pastor et al. 2013). The primed defense state permits a faster and stronger induction of immune responses to attackers (Conrath 2011; Conrath et al. 2001; Pastor et al. 2013). Hence, defense priming is an adaptive plant response that increases the responsiveness of the innate immune system. Priming can augment inducible defense responses in both local and systemic plant parts. Previous research has revealed that priming can be based on enhanced accumulation of defense signaling proteins, such as MAPKs or WRKY transcription factors (Beckers et al. 2009; Van der Ent et al. 2009). Jaskiewicz and associates (2011) suggested that defense priming during systemic acquired resistance is also associated with posttranslational modifications of histone $\mathrm{H} 3$ and $\mathrm{H} 4$, pointing to involvement of epigenetic mechanisms. Recent publications have shown that some IR responses of Arabidopsis and tomato (Solanum lycopersicum) can be transmitted to progeny (Luna et al. 2012; Rasmann et al. 2012; Slaughter et al. 2012), demonstrating a partially epigenetic basis of defense priming. It is also well documented that priming-inducing treatments can increase the responsiveness of the response pathways to defense hormones, such as salicylic acid (SA), jasmonic acid, and abscisic acid (ABA) (Jakab et al. 2005; Pozo et al. 2008; Ton and Mauch-Mani 2004; Van der Ent et al. 2009; Ton et al. 2005), explaining their involvement in the corresponding induced resistance phenomena.

Some chemicals, such as benzothiadiazole, azelaic acid, and $\beta$-aminobutyric acid (BABA), have been demonstrated to trigger IR responses against pathogens (Friedrich et al. 2003; Kessmann et al. 1994). When applied in modest doses, the resistanceinducing activity of these chemicals is based on defense priming, (Conrath et al. 2001; Jung et al. 2009; Pastor et al. 2013). 
Augmentation of SA-dependent defenses upon biotrophic infections is a common response to all three chemicals. Priming upon treatment with relatively low concentrations of BABA is not associated with major fitness costs (van Hulten et al. 2006) and has emerged as a very effective inducer of both SA-dependent and SA-independent IR responses (Ton et al. 2005; Van der Ent et al. 2009; Zimmerli et al. 2000). Consequently, this nonprotein amino acid protects plants against a wide range of pathogens, including necrotrophic pathogens such as Plectosphaerella cucumerina, Botrytis cinerea, and Alternaria brassicicola; and (hemi)-biotrophic pathogens such as Hyaloperonospora arabidopsidis, Pseudomonas syringae, and Pectobacterium carotovorum; and abiotic stress (Flors et al. 2008; Jakab et al. 2001, 2005; Po-Wen et al. 2013; Ton and Mauch-Mani 2004; Ton et al. 2005; Zimmerli et al. 2000). The SA-independent component of BABA-IR is associated with priming of callose deposition and requires intact ABA signaling (Flors et al. 2008; Ton and Mauch-Mani 2004).

Production of ROS is known to be one of the earliest events in response to microbe recognition (Wojtaszek 1997). ROS are byproducts of the reduction of molecular oxygen. The equilibrium between ROS scavenging and ROS synthesis safeguards primary metabolism during stress tolerance responses (Apel and Hirt 2004; Gechev and Hille 2005; Laloi et al. 2007; Miller et al. 2007; Pei et al. 2000). Plants have enzymatic and nonenzymatic strategies to maintain this equilibrium. Scavenging systems, such as catalases (CATs), peroxidases (e.g., ascorbate peroxidase and glutathione peroxidase), superoxide dismutase, and the nonenzymatic ascorbate acid/glutathione (ASA/GSH) cycle are ubiquitous in all cell compartments, and highlight the importance of ROS homeostasis for cellular physiology. This multifaceted role of ROS makes it difficult to pinpoint a specific function of ROS in plant defense. In addition to direct toxicity of $\mathrm{H}_{2} \mathrm{O}_{2}$, ROS also act as important extracellular and intracellular signaling molecules (D'Autreaux and Toledano 2007; Foyer and Noctor 2005a and b; Laloi et al. 2004; Meng et al. 2010; Mittler et al. 2011). Among them, $\mathrm{H}_{2} \mathrm{O}_{2}$ and $\mathrm{O}_{2}{ }^{-}$ and the reactive nitrogen species NO show specific reactivity with proteins, making them suitable for various signaling purposes (D'Autreaux and Toledano 2007; Spoel et al. 2010; Tada et al. 2008). To accurately develop this stress-related signaling function, ROS production must be tightly regulated to ensure specific responses along different cellular targets (D'Autreaux and Toledano 2007; Desikan et al. 2008; Foyer and Noctor 2005a and b; Miller et al. 2009; Neill et al. 2002). $\mathrm{H}_{2} \mathrm{O}_{2}$ can diffuse across membranes and is relatively stable. Therefore, it is the main ROS for extracellular cell-to-cell communication. ROS signaling can have a profound impact on nuclear gene expression that could encode for defense-related genes and pathogen-inducible transcription factors (Gadjev et al. 2006).

The signal transduction from ROS production to gene expression remains poorly understood. This process likely involves redox-dependent modifications of signaling proteins at Cys residues (Hancock et al. 2006; Jonak et al. 2002; Spoel and Loake 2011). Other putative mechanisms are direct sensing of ROS through redox-sensitive elements in transcription factor proteins (Mou et al. 2003; Neill et al. 2002) or metabolites implicated in redox homeostasis such as GSH (Ghanta and Chattopadhyay 2011; Ghanta et al. 2011) and ASA (Arrigoni and De Tullio 2002; Pastori et al. 2003). Further evidence for ROS participation in defense comes from the crosslinking of phenolics during papillae formation (Lamb and Dixon 1997). Callose is also part of cell wall appositions and accumulates in a coordinated fashion with $\mathrm{H}_{2} \mathrm{O}_{2}$ (Luna et al. 2011). Both ROS and callose are PAMP inducible. The bacterial PAMP Flg22, a 22-amino sequence of the conserved N-terminal part of flagellin (Felix et al. 1999; Gómez-Gómez and Boller 2000) and the fungal PAMP chitosan, a randomly distributed $\beta$-(1,4)-linked polymer of D-glucosamide and acetylglucosamine (Iriti and Faoro 2009), are widely used to study the PTI responses in plants. Previously, we observed that the timing of ROS and callose deposition in response to both PAMPs differs substantially. For instance, $\mathrm{H}_{2} \mathrm{O}_{2}$ and callose deposition co-localized upon chitosan treatment, but not in response to Flg22 treatment (Luna et al. 2011). Because priming of defense against necrotrophic pathogens is mediated by early accumulation of callose (Flors et al. 2008; García-Andrade et al. 2012; Ton and Mauch-Mani 2004), and $\mathrm{H}_{2} \mathrm{O}_{2}$ and callose production are spatially and temporally coordinated responses upon treatment with the fungal PAMP chitosan (Luna et al. 2011), we hypothesized that ROS homeostasis plays an important role in the participation of defense priming against fungal pathogens.

To explore the role of ROS signaling in defense priming, we studied the immune response of BABA-primed plants to challenge treatment with Flg22, chitosan, and the necrotrophic pathogen Plectosphaerella cucumerina. We show that BABA primes immune responses to the fungal PAMP chitosan but not in response to challenge with the bacterial PAMP Flg22. In addition, we demonstrate that the primed immune response to chitosan and $P$. cucumerina requires redox regulation mediated by respiratory burst oxidase protein $D(R B O H D)$ and GSHI.

\section{RESULTS}

\section{Enhanced production of $\mathrm{H}_{2} \mathrm{O}_{2}$ and callose marks the BABA-primed immune response to chitosan but not to Flg22.}

ROS and callose are induced in response to MAMPs or PAMPs (Galletti et al. 2008; Gómez-Gómez et al. 1999; Luna et al. 2011). To investigate whether BABA augments the plant's reaction to PAMPs, we used a previously optimized hydroponic cultivation system in Murashige and Skoog (MS) medium (Clay et al. 2009; Luna et al. 2011). Different BABA concentrations were applied to 7-day-old seedlings to obtain the optimal concentration for defense priming in hydroponically grown Arabidopsis (Supplementary Fig. S1). $\mathrm{H}_{2} \mathrm{O}_{2}$ and callose deposition were examined at 1 day after PAMP application, using digital quantification of 3,3'-diaminobenzidine (DAB) and aniline-blue stained cotyledons, respectively. This analysis revealed that BABA at $1 \mathrm{ppm}$ is the minimal concentration to mediate augmented induction of ROS and callose by chitosan, which was selected for all subsequent experiments. Strikingly, in all instances, pretreatment with BABA failed to augment $\mathrm{H}_{2} \mathrm{O}_{2}$ and callose production upon Flg22 treatment (Fig. 1). Hence, in cotyledons, BABA-induced priming specifically acts upon the pathways controlling chitosan-induced $\mathrm{H}_{2} \mathrm{O}_{2}$ and callose, whereas regulation of Flg22-induced $\mathrm{H}_{2} \mathrm{O}_{2}$ and callose is unaffected by BABA in the hydroponic growth system.

\section{Primed production of chitosan-induced $\mathrm{H}_{2} \mathrm{O}_{2}$ and callose requires an intact $\mathrm{ROS}$ homeostasis.}

To assess the relevance of ROS metabolism in priming of chitosan-induced $\mathrm{H}_{2} \mathrm{O}_{2}$ and callose, we analyzed mutants in ROS production or scavenging. Mutant $r b o h D$ is blocked in superoxide-generating NADPH oxidase gene RBOHD (Pógany et al. 2009), which reduces its capacity to generate PAMP-induced $\mathrm{H}_{2} \mathrm{O}_{2}$ (Luna et al. 2011). Mutants cat 2 and vtcl) are impaired in peroxisomal catalase (Bueso et al. 2007) and production of L-ASA (Conklin et al. 2000), respectively, and sustain exaggerated $\mathrm{H}_{2} \mathrm{O}_{2}$ production due to their reduced ROS-scavenging capacity (Luna et al. 2011). The pad2 mutant is impaired in $\gamma$-glutamilcysteine synthetase (GSHI) (Parisy et al. 2007), the first dedicated step of GSH biosynthesis, causing disruption of 
the Halliwell-Asada cycle controlling ROS homeostasis (Foyer and Noctor 2005a and b). Our experiments showed that application of chitosan to the rbohD mutant triggers $\mathrm{H}_{2} \mathrm{O}_{2}$ and callose deposition (Fig. 2) but that pretreatment with BABA fails to mediate augmented production of $\mathrm{H}_{2} \mathrm{O}_{2}$ and callose. Hence, RBOHD is essential for priming of chitosan-induced $\mathrm{H}_{2} \mathrm{O}_{2}$ and callose. The mutant pad 2 showed wild-type levels of chitosaninduced $\mathrm{H}_{2} \mathrm{O}_{2}$ and callose but pretreatment of pad2 with BABA also failed to increase chitosan-induced $\mathrm{H}_{2} \mathrm{O}_{2}$ and callose, thus indicating that GSH1 (PAD2), like $R B O H D$, is required to mediate BABA-primed expression of chitosan-induced $\mathrm{H}_{2} \mathrm{O}_{2}$ and callose. As expected, vtcl and cat 2 showed strongly augmented levels of $\mathrm{H}_{2} \mathrm{O}_{2}$ and callose under all conditions tested (Luna et al. 2011) (Fig. 2). However, in both mutants, BABA failed to augment chitosan-induced $\mathrm{H}_{2} \mathrm{O}_{2}$ and callose, most likely because these responses had reached saturation.

\section{Mutants edr1 and lin1 show constitutive priming of Flg22- and chitosan-induced $\mathrm{H}_{2} \mathrm{O}_{2}$ and callose.}

To determine whether ROS production and callose deposition are general mechanisms of priming, we compared the effects of BABA in wild-type plants with the phenotype of mutants that are constitutively primed for defense (edrl and lin1) (Camañes et al. 2012; van Hulten et al. 2006). In the absence of PAMP treatment, $e d r l$ and $\operatorname{lin} 1$ did not accumulate elevated levels of callose or $\mathrm{H}_{2} \mathrm{O}_{2}$ (Fig. 3), whereas these defenses were clearly augmented upon challenge with Flg22 and chitosan in comparison with wild-type plants. These results indicate that augmented accumulation of PAMP-induced $\mathrm{H}_{2} \mathrm{O}_{2}$ and callose are common hallmarks of defense priming. However, in contrast to edrl- and linl-induced priming, BABA failed to prime Flg22-triggered $\mathrm{H}_{2} \mathrm{O}_{2}$ and callose production (Fig. 3). This difference highlights that, under our experimental conditions, constitutive priming in $e d r l$ and linl is based on partially different mechanisms than BABA-induced priming in wild-type plants.

\section{BABA alters ROS-dependent gene expression} and promotes oxidative cell status during PTI.

To investigate whether BABA influences ROS-dependent gene transcription upon chitosan treatment, we profiled chitosan-dependent expression of RBOHD, GSH1, VTC1, and CAT2 in mock- or BABA-treated plants. In mock-treated plants, chitosan induced $R B O H D, A P X 1$, and $G S H 1$ while it repressed $C A T 2$ expression (Fig. 4). This expression profile indicates that PTI is associated with a simultaneous increase in production and scavenging of ROS. Pretreatment with BABA directly enhanced $G S H 1$ and $V T C 1$ expression in unchallenged plants; this enhancement may not allow further induction following chitosan challenge. Similarly, BABA induced $R B O H D$ expression. Contrastingly, BABA repressed chitosan-induced $A P X I$ and GSH1 expression (Fig. 4), suggesting that $A P X 1$ and GSHI repression could contribute to an increased oxidative status of the cell during expression of chitosan-induced PTI. To test this hypothesis, we measured GSH/GSSG ratios. Pretreatment with BABA repressed the cellular GSH/GSSG ratio following chitosan treatment (Fig. 4B), causing an enhanced oxidative status of the cell during the augmented defense response. To-
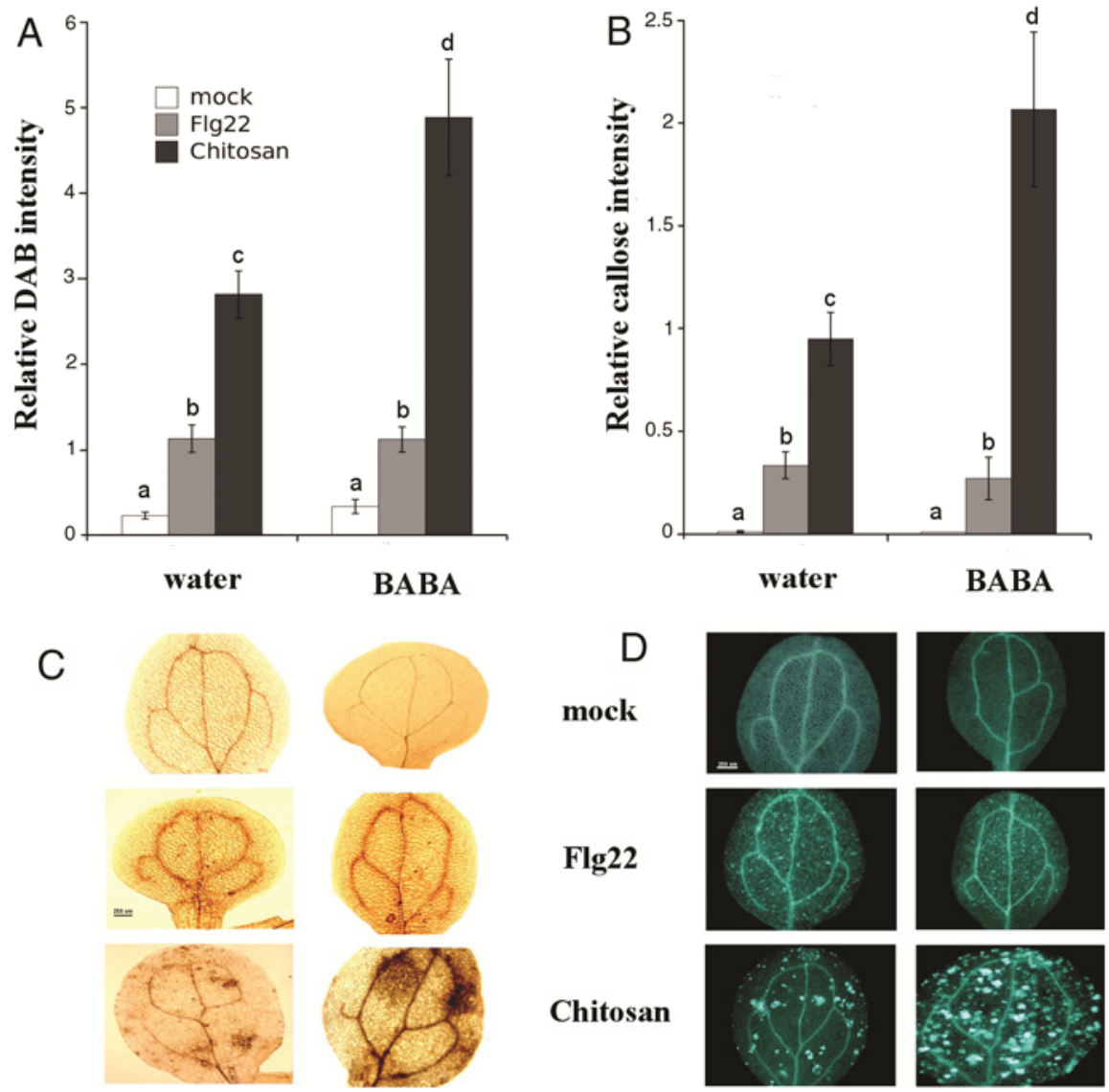

Fig. 1. Priming effect upon Flg22 and chitosan treatment. A, $\mathrm{H}_{2} \mathrm{O}_{2}$ production and $\mathbf{B}$, callose accumulation upon treatment of $1 \mu \mathrm{M}$ Flg 22 or $0.01 \%$ chitosan. Cotyledons were treated with $\beta$-aminobutyric acid $(\mathrm{BABA})$ at $1 \mathrm{ppm}$ as a priming agent, $24 \mathrm{~h}$ prior to pathogen-associated molecular pattern treatment. $\mathrm{DAB}=$ 3,3'-diaminobenzidine. Data shown are average values ( \pm standard error of the mean; $n>15$ ) of relative staining intensities from four different experiments. Different letters indicate statistically significant differences between treatments (Fisher's least significant differences test; $\alpha=0.05$ ). $\mathbf{C}$ and $\mathbf{D}, \mathrm{Representative}$ pictures of $\mathrm{H}_{2} \mathrm{O}_{2}$ production and callose accumulation, respectively, in these conditions. 
gether, these results show that defense priming by BABA correlates with a diminished reducing capacity of the cell during expression of PTI, allowing for augmented accumulation of ROS. Why BABA-primed plants show a simultaneous increase in the expression of ROS-generating (RBOHD) and ROS-scavenging (VTC1) genes remains unknown but compartmentalization of antioxidants in different cell organelles may offer an explanation for this finding (Conklin and Barth 2004; Queval et al. 2011).

\section{Primed immune expression against the necrotroph}

\section{$P$. cucumerina is associated}

\section{with augmented deposition of $\mathrm{H}_{2} \mathrm{O}_{2}$ and callose.}

BABA-IR against necrotrophic pathogens is based on a faster and stronger accumulation of callose-rich papillae depositions (Flors et al. 2008; Ton and Mauch-Mani 2004). To verify whether accumulation of $\mathrm{H}_{2} \mathrm{O}_{2}$ and callose in hydroponically cultivated Arabidopsis seedlings can be extrapolated to the interaction between soil-grown Arabidopsis and a necrotrophic pathogen, we tested $\mathrm{H}_{2} \mathrm{O}_{2}$ and callose accumulation in primed and unprimed Arabidopsis after inoculation with the nectrotrophic fungus $P$. cucumerina. Five-week-old plants were pretreated either with water or $150 \mu \mathrm{M}$ BABA and subsequently challenged with $P$. cucumerina. BABA-treated plants showed strongly augmented accumulation of callose and $\mathrm{H}_{2} \mathrm{O}_{2}$ following $P$. cucumeria infection, which correlated with reduced disease development (Fig. 5). Thus, primed immune expression against $P$. cucumerina is associated with coordinated potentiation of $\mathrm{H}_{2} \mathrm{O}_{2}$ and callose deposition.

\section{RBOHD and GSH1 are critical for expression} of primed immunity against $P$. cucumerina.

To further investigate the role of ROS homoeostasis during expression of primed immunity against $P$. cucumerina, we

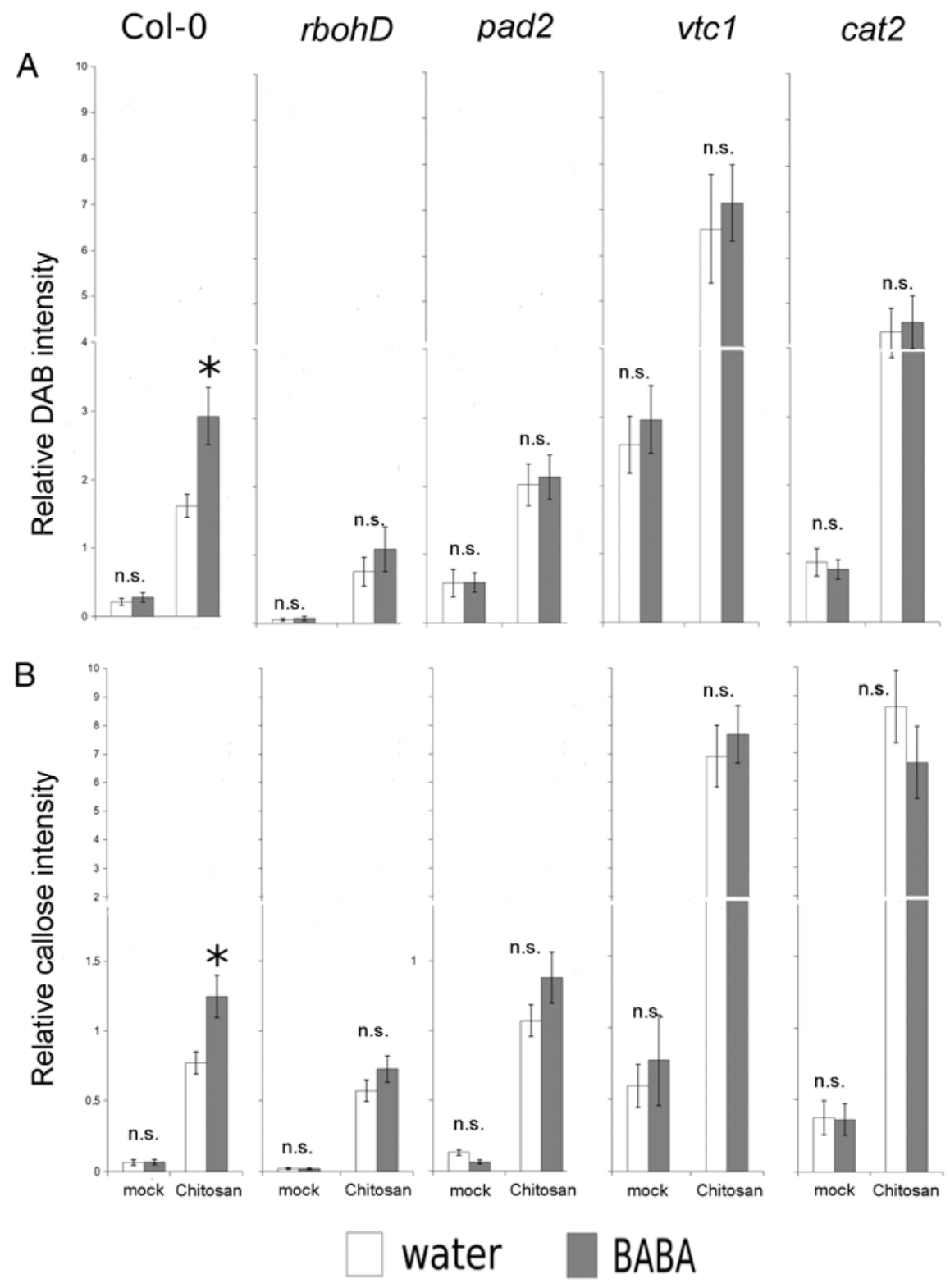

Fig. 2. Priming phenotype in reactive oxygen species (ROS) homeostasis-blocked plants. $\mathbf{A}, \mathrm{H}_{2} \mathrm{O}_{2}$ production and $\mathbf{B}$, callose accumulation upon treatment of $0.01 \%$ chitosan. Cotyledons were treated with $\beta$-aminobutyric acid (BABA) at $1 \mathrm{ppm}$ as a priming agent, $24 \mathrm{~h}$ prior to pathogen-associated molecular pattern treatment. Data shown are average values ( \pm standard error of the mean; $n>15$ ) of relative staining intensities (relative to the leave surface) from four different experiments. Asterisks indicate statistically significant changes in response to BABA treatment (Student's $t$ test; $\alpha=0.05$ ); n.s. $=$ no statistically significant difference between water- and BABA-treated seedlings. 
tested rbohD, pad2, vtc1, and cat 2 for BABA-IR, $\mathrm{H}_{2} \mathrm{O}_{2}$ production, and callose accumulation. Mutants rbohD and pad2 failed to express BABA-IR against $P$. cucumerina (Fig. 6A), which coincided with lack of augmented production of $\mathrm{H}_{2} \mathrm{O}_{2}$ and callose. Unlike rbohD, which showed wild-type levels of basal resistance to $P$. cucumerina, the pad 2 mutant was more susceptible to the fungus (Fig. 6A). Hence, ROS production by $\mathrm{RBOHD}$ is necessary to mount a primed immune response but
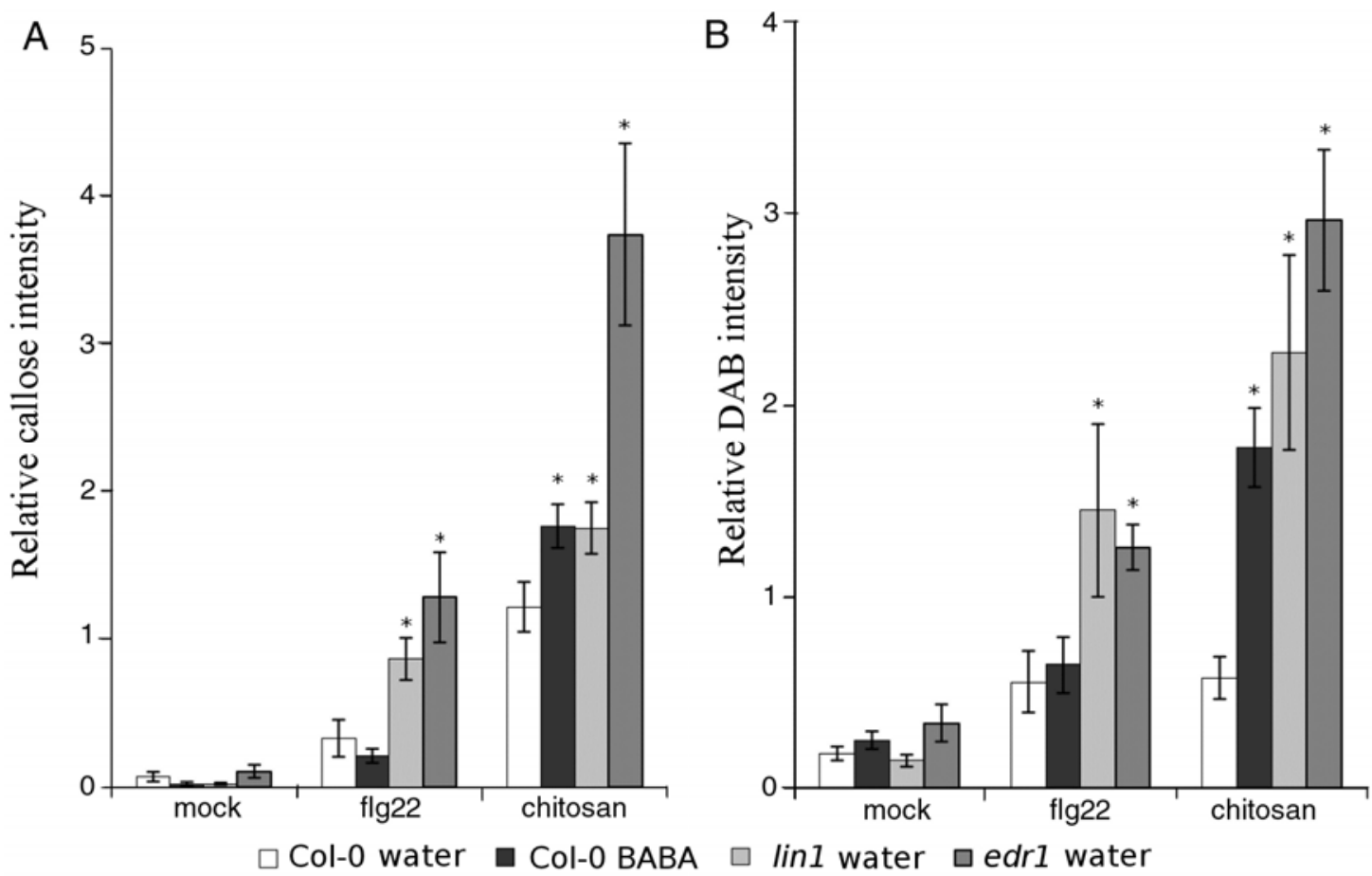

Fig. 3. $\mathrm{H}_{2} \mathrm{O}_{2}$ and callose accumulation in constitutively primed plants. $\mathbf{A}, \mathrm{H}_{2} \mathrm{O}_{2}$ production and $\mathbf{B}$, callose accumulation were quantified by determining the intensities of stained cotyledons treated with $1 \mu \mathrm{M}$ Flg22 or $0.01 \%$ chitosan. Only wild-type seedlings were both water- and $\beta$-aminobutyric acid (BABA; $1 \mathrm{ppm}$ )-treated; meanwhile, priming mutants were only water-treated. Asterisks indicate statistically significant differences compared with Col-0 watertreated plants. $\mathrm{DAB}=3,3^{\prime}$-diaminobenzidine. (Student's $t$ test; $\alpha=0.05$ ).

A
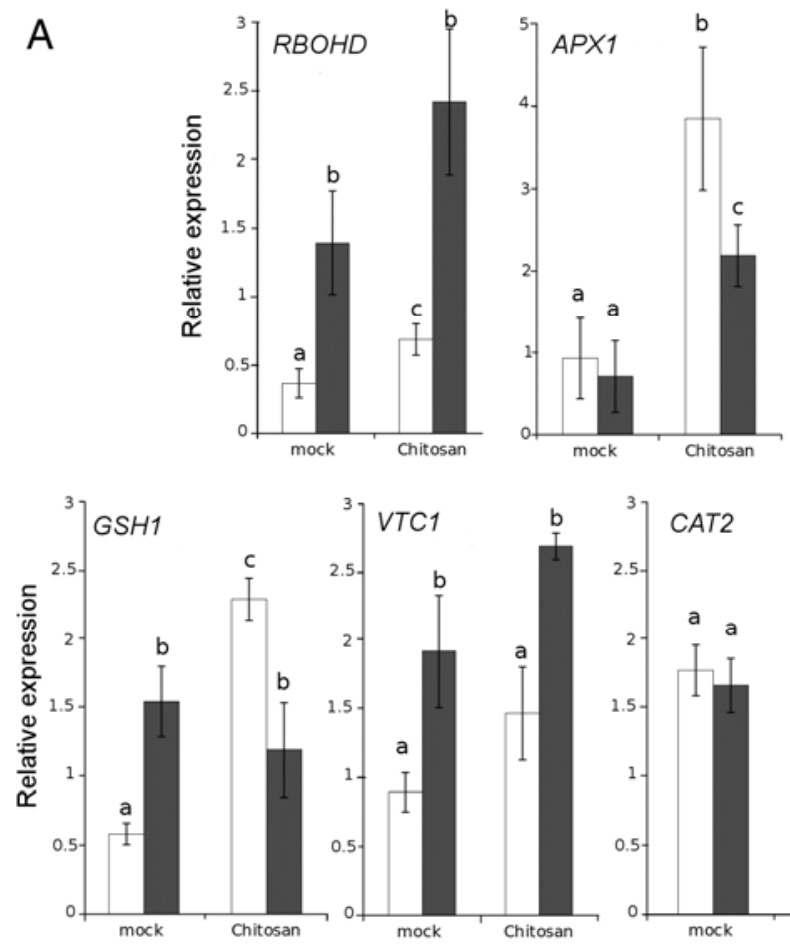
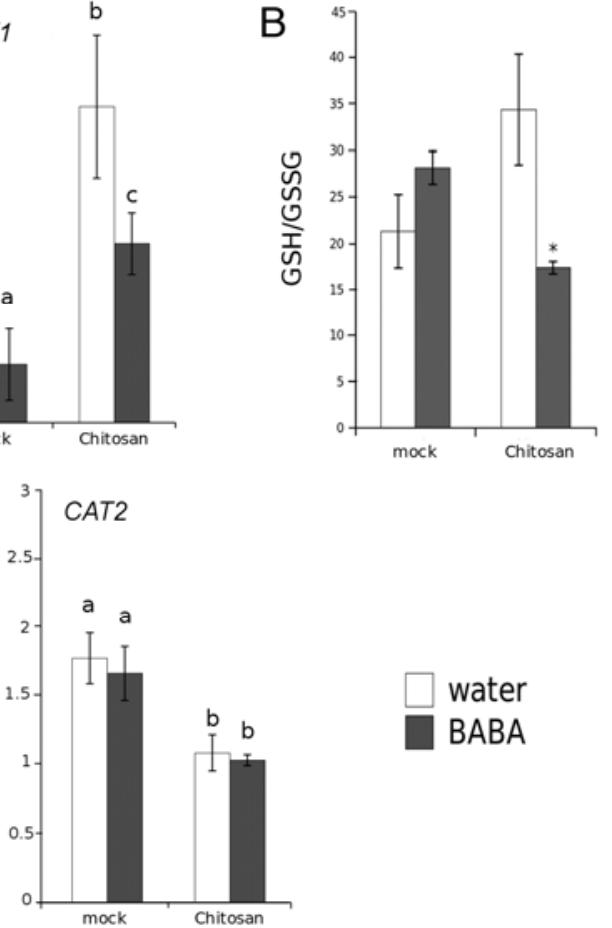

Fig. 4. Effect of chitosan over genes implicated in reactive oxygen species (ROS) homeostasis and redox cell environment. A, Quantitative reversetranscription polymerase chain reaction analysis of RBOHD, APX1, GSH1, VTC1, and CAT2 in seedlings pretreated for $24 \mathrm{~h}$ with $\beta$-aminobutyric acid (BABA) and after $24 \mathrm{~h}$ of chitosan treatment. Bars represent mean \pm standard deviation (SD), $n=3$ from three different experiments. Different letters represent statistical significant differences. (Fisher's least significant differences test; $\alpha=0.05$ ). B, Glutathione contents in Col-0 seedlings treated as described in A; the experiment has been repeated three times with similar results. Data shown are means \pm SD. Asterisk indicates statistically significant differences compared with water-treated seedlings (Student's $t$ test; $\alpha=0.01$ ). 
is not required for basal resistance against $P$. cucumerina, whereas GSH1 is necessary for both basal and primed immunity against $P$. cucumerina. The ROS-scavenging mutants $v t c l$ and cat 2 expressed normal levels of basal resistance and BABA-IR against $P$. cucumerina (Fig. 6A). However, as previously observed under hydroponic conditions (Fig. 2), these mutants are constitutively primed for $\mathrm{H}_{2} \mathrm{O}_{2}$ and callose deposition, which was also apparent after inoculation with $P$. $\mathrm{cucu}$ merina (Fig. 6B and C). To examine why vtcl and cat 2 are still capable of BABA-IR to $P$. cucumerina, we measured pathogen-induced camalexin, which acts sequentially after glucosinolate-mediated defense in basal resistance to Phytophthora brassicae (Schlaeppi et al. 2010). As was previously described by Ton and Mauch-Mani (2004), camalexin does not contribute to BABA-IR against Plectosphaerella cucumerina in wildtype Arabidopsis. In fact, BABA-treated plants showed even lower levels of camalexin accumulation than unprimed control plants following P. cucumerina infection (Ton and Mauch-
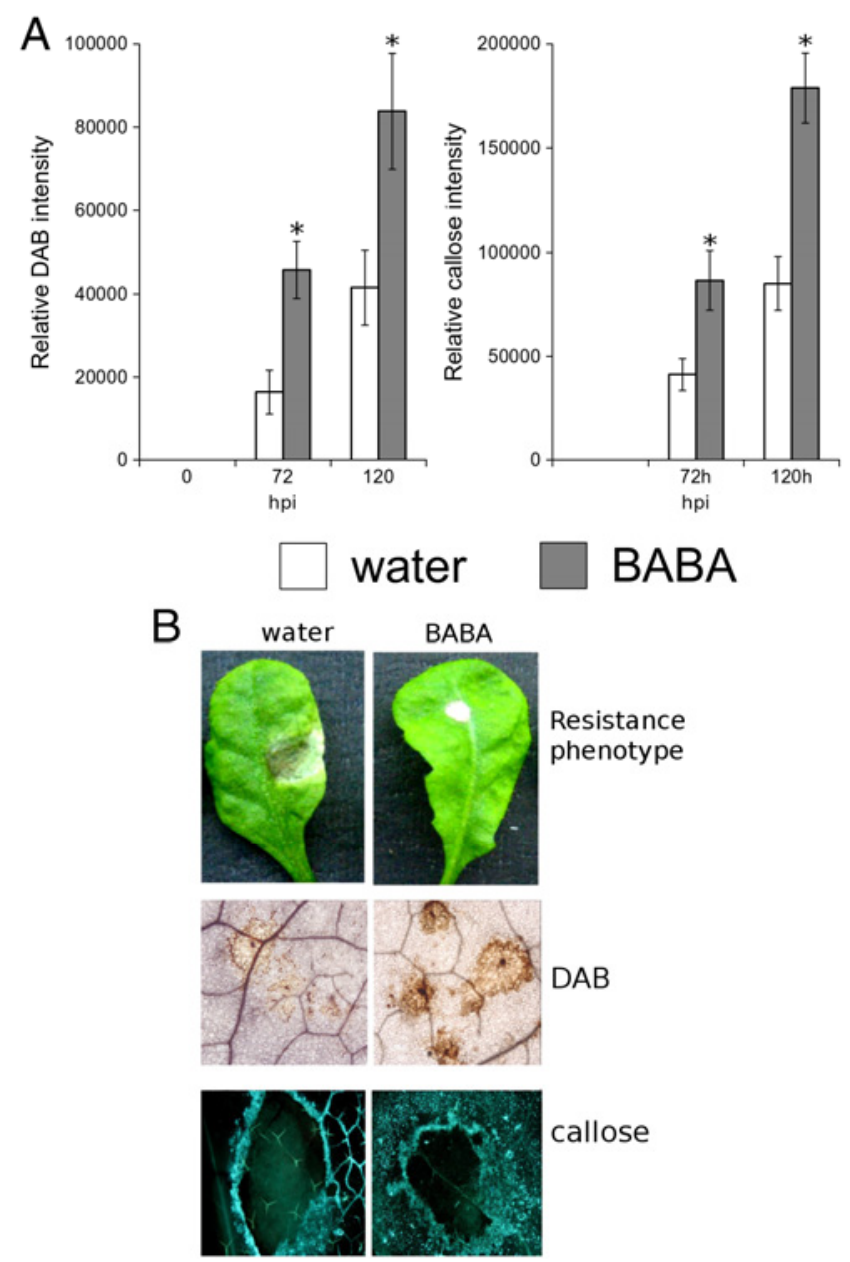

Fig. 5. $\mathrm{H}_{2} \mathrm{O}_{2}$ and callose accumulation in water- and $\beta$-aminobutyric acid (BABA)-treated Col-0 plants upon inoculation by Plectosphaerella сисиmerina. A, Five-week-old plants were soil-drenched with water or $150 \mu \mathrm{M}$ BABA. At 2 days after chemical treatment , 6 to 8 leaves per plant were challenged by applying $6-\mu$ d droplets containing $5 \times 10^{6}$ spores $\mathrm{ml}^{-1}$. Quantification was performed by determining the number of brown pixels (3,3'-diaminobenzidine [DAB]-staining) or yellow pixels (callose staining) on digital photographs of infected leaf areas at 72 and $120 \mathrm{~h}$ postinfection (hpi). Data shown are means \pm standard deviation $(n=8)$ of the relative number of brown or yellow pixels per photograph. Asterisks indicate significant differences between water- and BABA-treated and infected plants (Student's $t$ test; $\alpha=0.05$ ). B, Representative leaves of Col-0 plants after inoculation with $P$. cucumerina in control plants (left) and BABA treated plants (right).
Mani 2004), probably because the augmented callose barrier in BABA-treated plants was already effective in arresting $P$. cucumerina colonization. Our present results confirm that BABA-treated wild-type plants accumulate lower levels of camalexin following $P$. cucumerina infection (Supplementary Fig. S2). Interestingly, however, vtc1 and cat2 showed opposite patterns and accumulated augmented levels of pathogeninduced camalexin after $P$. cucumerina infection. Therefore, we conclude that the intact BABA-IR response in $v t c 2$ and cat 2 is not based on augmented ROS or callose deposition but, instead, on augmented accumulation of camalexin.
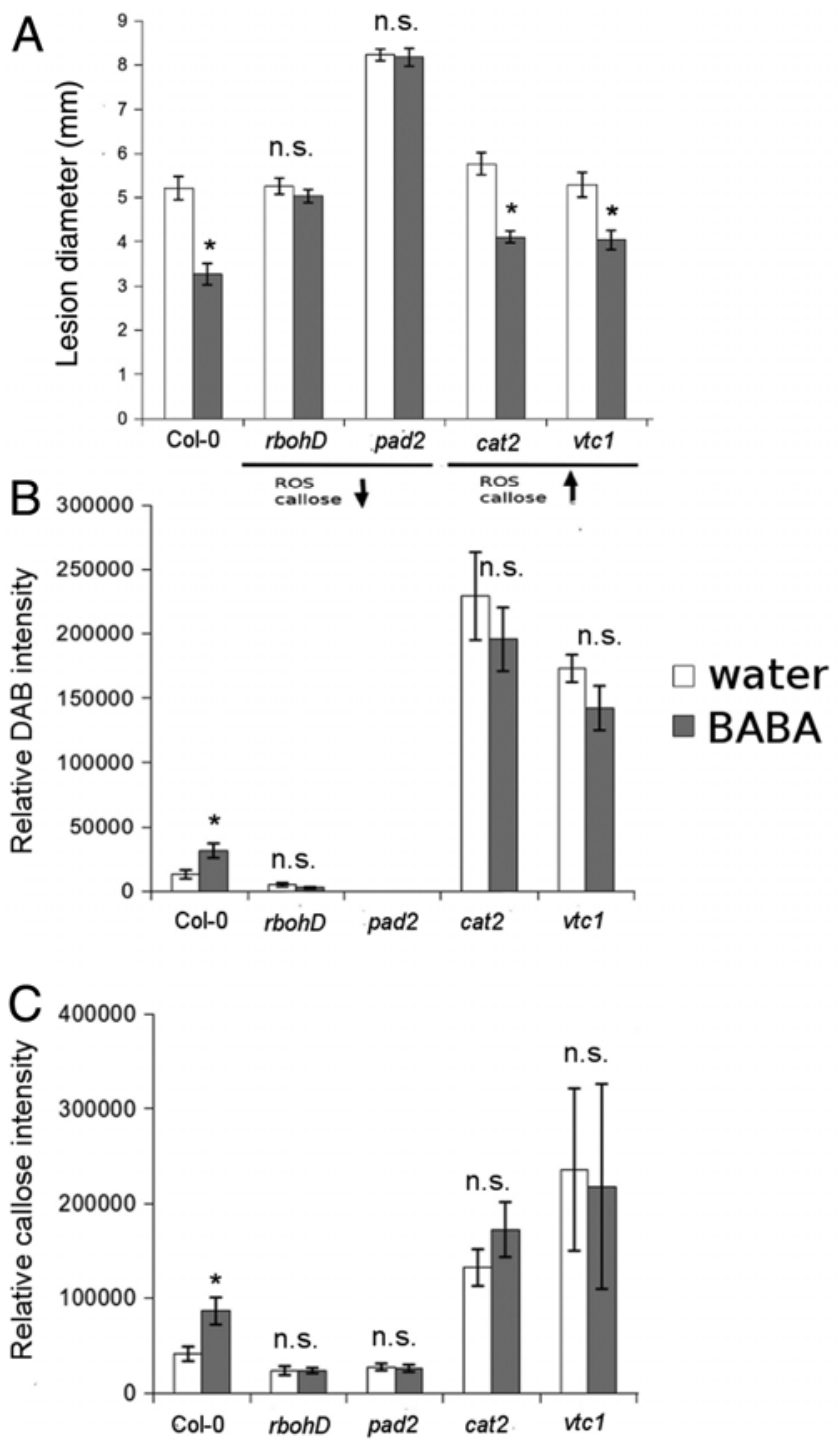

Fig. 6. $\beta$-Aminobutyric acid (BABA) induced resistance, $\mathrm{H}_{2} \mathrm{O}_{2}$, and callose accumulation in Col-0 and mutants in reactive oxygen species (ROS) homeostasis upon infection. A, Lesion size in water- and BABA-treated 5-week-old plants after 6 days postinfection with Plectosphaerella cucumerina. Values are means and \pm standard deviation (SD) $(n=15)$. Fiveweek-old plants were soil-drenched with water or $150 \mu \mathrm{M}$ BABA. At 2 days after chemical treatment, 6 to 8 leaves per plant were challenged by applying 6 - $\mu$ d droplets containing $5 \times 10^{6}$ spores $\mathrm{ml}^{-1}$. Quantification was performed by determining the number of yellow pixels (callose staining) or brown pixels (3,3'-diaminobenzidine [DAB] staining) on digital photographs of infected leaf areas. (Student's $t$ test; $\alpha=0.05$ ). B, DAB and $\mathbf{C}$, callose accumulation at $72 \mathrm{~h}$ postinfection in water- and BABA-treated plants. Asterisks indicate significant differences between BABA-treated and infected with respect to the water-treated and infected. Values are means and $\pm \mathrm{SD}(n=8)$; n.s. = no statistically significant difference between water- or BABA-treated and infected seedlings (Student's $t$ test; $\alpha=$ $0.05)$. 
BABA primes transcription of $R B O H D$ and $V T C 1$ but represses transcription

of $A P X 1$ and $G S H 1$ after pathogen attack.

To further study the role of redox homeostasis during BABAIR to $P$. cucumerina, we analyzed ROS-related gene transcription in mock- and BABA-treated plants at 48 and $72 \mathrm{~h}$ after $P$. cucumerina infection. In agreement with our previous finding that RBOHD is critical for BABA-IR to P. cucumerina (Fig. 6), BABA primed pathogen-induced transcription of $R B O H D$ in wild-type plants (Fig. 7A). Interestingly, this transcriptional priming was absent in the pad2 mutant (Supplementary Fig. S3), which concomitantly failed to express BABA-IR against $P$. cucumerina (Fig. 6A). In addition, BABA suppresses $A P X 1$ expression after infection by the necrotroph. Conversely, GSH1 was directly induced by BABA but was repressed following subsequent pathogen infection. Finally, VTC1 expression showed strongly augmented induction in BABA-treated plants at $48 \mathrm{~h}$. This result, together with the fact that vtcl accumulates augmented levels of $\mathrm{H}_{2} \mathrm{O}_{2}$ under hydroponic conditions (Fig. 5), suggests that BABA favors an oxidative cell status during pathogen infection. Indeed, pretreatment with BABA consistently decreased GSH to oxidized glutathione (GSSG) ratios during infection by $P$. cucumerina, indicating that BABA-induced priming of ROS production is based on an increase in the oxidative cell status during pathogen infection. This conclusion is corroborated by our finding that BABA-induced suppression of GSH/GSSG after $P$. cucumerina infection is absent in $v t c 1$, cat2, and $r b o h D$ (Supplementary Fig. S4).

\section{DISCUSSION}

Our study demonstrates that augmented defense reactions in primed plants are partially due to an increased capacity to accumulate ROS. Because ROS function as second messengers of a variety of cellular defense responses (Sagi and Fluhr
2006), a reduced capacity to scavenge pathogen-inducible ROS offers a mechanistic explanation for increased resistance in primed plants. We have previously reported that BABAinduced defense priming against $P$. cucumerina requires intact ABA signaling (Flors et al. 2008; Ton and Mauch-Mani 2004). Our present study has revealed that BABA-IR against $P$. $\mathrm{cucu}$ merina is also dependent on $\mathrm{H}_{2} \mathrm{O}_{2}$ accumulation, which has a direct influence on callose deposition. Therefore, we propose that ABA, ROS, and callose are interrelated components in the regulation of BABA-induced resistance against necrotrophic pathogens.

Our study has shown that BABA-induced defense priming augments chitosan-induced defense but not Flg22-induced defense (Fig. 1). Although both PTI reactions share similar defense components (Luna et al. 2011), the regulation of plant responses to fungal and bacterial PAMPs is different. Singh and associates (2012) showed that BABA at $20 \mathrm{ppm}$ applied as a soil drench results in augmented callose deposition upon flg22 treatment. By contrast, we only observed augmented callose deposition in BABA-treated plants after chitosan treatment. We propose that this discrepancy originates from differences in the age of the plants (5-week-old versus 2-week-old plants) and experimental conditions (soil versus hydroponics). We applied Flg22 to growth medium of hydroponically cultivated seedlings, whereas Singh and associates (2012) and PoWen and associates (2013) infiltrated leaves from soil-grown plants with Flg22. The latter method bypasses the first layers of defense by introducing the PAMP directly into the apoplast, which could explain the discrepancy. We also tested the capacity of BABA to prime callose and ROS deposition at different concentrations, ranging from 0.1 to $20 \mathrm{ppm}$. Interestingly, only 1 and 5 ppm-primed chitosan induced ROS and callose, demonstrating a hormetic dose-response relationship for BABAinduced priming in hydroponically cultivated Arabidopsis. Furthermore, these chitosan-induced callose deposits resemble those observed in nonhost interactions described by Ham and
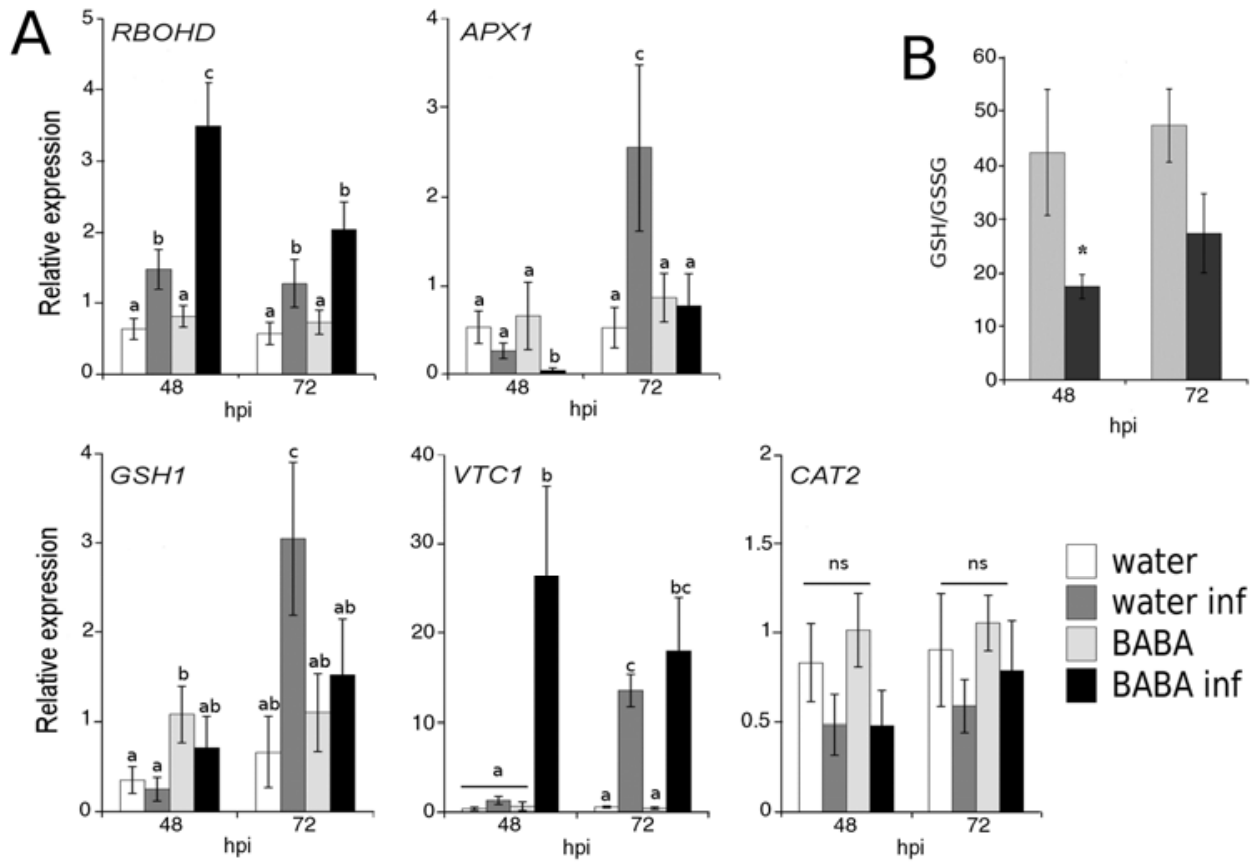

Fig. 7. Priming effect in reactive oxygen species (ROS) homeostasis-related gene expression and glutathione (GSH) contents. A, Quantitative reverse-transcription polymerase chain reaction (RT-PCR) analysis of RBOHD, APX1, GSH1, VTC1, and CAT2 in 5-week-old-plants pretreated with $\beta$-aminobutyric acid (BABA) 2 days before infection with Plectosphaerella cucumerina. RNA was isolated from infected leaves at 0,48 , and 72 h after inoculation, converted to cDNA, and subjected to quantitative RT-PCR. Values are normalized at $t=0 \mathrm{~h}$ (initial conditions). Bars represent mean \pm standard deviation (SD), $n=3$ independent replicates (Fisher's least significant differences test; $\alpha=0.05$ ). B, GSH contents in Col-0 seedlings treated as described in A. Data shown are means \pm SD. Asterisk indicates statistically significant differences compared with water-treated seedlings (Student's $t$ test; $\alpha=0.05)$. 
co-workers (2007), named "big callose". Neither small callose induced by flg22 or big callose induced by chitosan were associated with cell necrosis (data not shown).

Our study shows that Arabidopsis mutants in either ROS generation or scavenging are blocked or deregulated in BABAinduced priming of callose. In support of our data, DubreuilMaurizi and associates (2010) demonstrated that treatments with diphenyleneiodonium, a specific inhibitor of $R B O H D$, blocks BABA-IR in grape plants against Plasmopara viticola. We determined expression of the main genes involved in ROS metabolism and observed direct induction of $R B O H D, G S H 1$, and VTCl after BABA treatment. However, ROS and callose production were not activated by BABA in the absence of chitosan. This suggests that the contribution of RBOHD, GSH1, and VTC1 to augmented ROS and callose deposition requires post-transcription activation.

Mutants rbohD and pad2 are impaired in BABA-induced priming of $\mathrm{H}_{2} \mathrm{O}_{2}$ and callose, and concomitantly failed to express BABA-IR against Plectosphaerella cucumerina (Figs. 2 and 6). This indicates a causal relationship between BABA-IR, on the one hand, and augmented production of $\mathrm{H}_{2} \mathrm{O}_{2}$ and callose, on the other hand. Accordingly, we predicted that disruption of GSH1 in the pad2 mutant would lead to increased levels of $\mathrm{H}_{2} \mathrm{O}_{2}$, because the mutant accumulates reduced levels of glutathione (Parisy et al. 2007). However, this hypothesis could not be confirmed (Figs. 2 and 6B). The pad 2 mutant is impaired in cell membrane depolarization (Dubreil-Maurizi et al. 2011), which takes place prior to ROS production. This could explain why this mutant accumulates unexpectedly low levels of $\mathrm{H}_{2} \mathrm{O}_{2}$ and is concomitantly impaired in BABA-IR. Another unexpected turn was our finding that cat 2 and $v t c 1$ accumulate constitutively enhanced levels of callose and $\mathrm{H}_{2} \mathrm{O}_{2}$ upon pathogen attack but, nevertheless, expressed wild-type levels of basal resistance and BABA-IR against $P$. cucumerina (Fig. 6A). Based on these results, we can only conclude that augmented deposition of ROS and callose does not contribute to either basal resistance or BABA-IR in cat 2 and $v t c 1$. In trying to find an explanation for such an unexpected outcome, we studied the dynamics of pathogen-induced phytoalexin accumulation, which had previously been reported to act as a secondary defense barrier in Arabidopsis against Phytophthora brassica (Schlaeppi et al. 2010). As reported by Ton and Mauch-Mani (2004), Plectosphaerella cucumerina-induced camalexin showed repressed accumulation in BABA-treated wild-type plants. This finding can be explained by the possibility that augmented callose deposition in BABA-treated wild-type plants precedes camalexin production. By contrast, vtcl and cat 2 displayed augmented levels of pathogen-induced camalexin following BABA treatment. Hence, BABA-IR in $v t c l$ and cat 2 is associated with augmented production of camalexin. Considering that ROS and callose in vtcl and cat 2 do not contribute to resistance against $P$. $c u c u$ merina (Fig. 6), our camalexin essays suggest that BABA-IR in $v t c 1$ and cat 2 is based on camalexin priming. These results also illustrate that BABA primes multiple defense barriers, which act sequentially and redundantly in mounting resistance to fungal pathogens. Indeed, these observations provide a reason for BABA-IR in cat2; however, the elevated levels of camalexin in cat2 suggest that this mutant may still have other unknown defects on its basal defense because it is not more resistant than wild-type plants.

Our transcriptional analysis of genes involved in redox homeostasis revealed augmented RBOHD expression in BABAprimed plants, whereas genes involved in ROS scavenging do not change or are downregulated in the hydroponic system (VTC1 and CAT2). RBOHD transcripts and ROS accumulation are also primed by BABA in grapevine against infection by the oomycete Plasmopara viticola (Dubreuil-Maurizi et al. 2010), where the resulting augmentation in oxidative burst could play an important role in defense signaling. We found that the rbohD mutant challenged with $P$. cucumerina failed to express BABA-IR, even though it was unaffected in basal resistance. Similarly, it has been reported that rbohD displays normal levels of susceptibility to A. brassicicola and B. cinerea (Galletti et al. 2008; Pógany et al. 2009), suggesting that $R B O H D$ is not required for basal resistance against necrotrophs. However, BABA-induced RBOHD expression may contribute to enhanced resistance in coordination with reduced expression of $A P X 1$, which encodes a critical peroxidase for maintaining redox control and homeostasis in the cell (Davletova et al. 2005). In this context, it is noteworthy that VTC1 and APX1 are both downregulated during the hypersensitive response (HR), contributing to toxic accumulation levels of $\mathrm{H}_{2} \mathrm{O}_{2}$ that trigger cell death (de Pinto et al. 2006). Our experiments showed that priming by BABA augments $\mathrm{H}_{2} \mathrm{O}_{2}$ production without triggering a HR. On the contrary, BABA suppressed $A P X 1$ transcripts whereas it primes $R B O H D$ expression at early time-points (Fig. 7), increasing the ROS production. Upon infection, BABA also primes VTCl expression. This may contribute to keep a remaining pool of ASA available for the cell to keep $\mathrm{H}_{2} \mathrm{O}_{2}$ at high concentrations but always under a toxic threshold level. Elevated $\mathrm{H}_{2} \mathrm{O}_{2}$ levels affect the redox status in the $\mathrm{GSH}$ pool more than in the ASA/DHA ratio, and can easily shift to its oxidized form, GSSG (Noctor 2006; Noctor et al. 2012). In primed plants, VTCl expression is enhanced, but it does not correspond with increases in GSH1 transcripts. This gene regulation suggests an oxidized state of the cytoplasm induced by the high levels of $\mathrm{H}_{2} \mathrm{O}_{2}$. This is confirmed by the lower levels of GHS/GSSG in BABA-treated plants upon PAMP challenge or infection. Accordingly, this reduced GHS/GSSG is absent in all redox mutants that are unprotected by BABA.

Enhanced ROS production is a common feature in cells exposed to stress. Plants have evolved the ability to take advantage of these small molecules for signaling and defense. In this study, we have demonstrated that priming of chitosan- and pathogeninduced $\mathrm{H}_{2} \mathrm{O}_{2}$ and callose deposition requires an intact cellular machinery to generate and scavenge ROS. Furthermore, BABA-induced resistance against the necrotrophic pathogen Plectosphaerella cucumerina requires $\mathrm{RBOHD}$ and GSHI

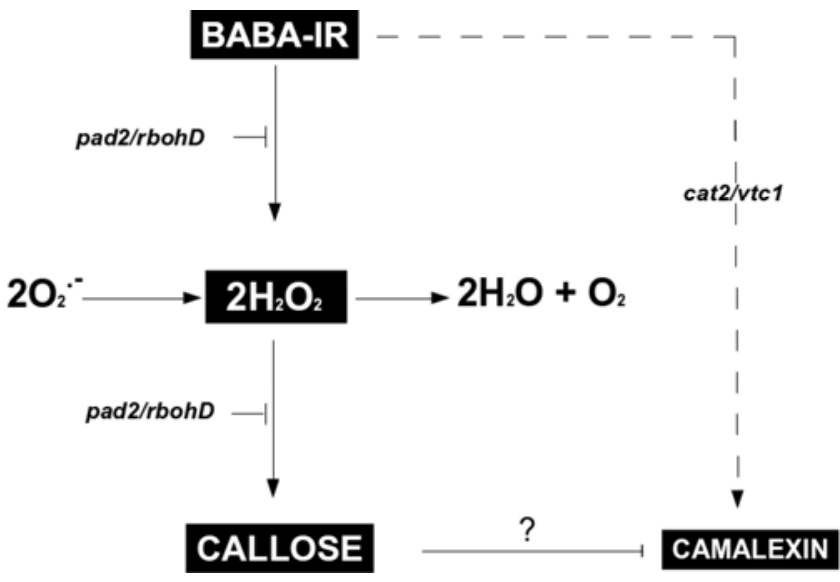

Fig. 8. Model of callose and $\mathrm{H}_{2} \mathrm{O}_{2}$ priming by $\beta$-aminobutyric acid (BABA) upon challenge. In wild-type plants, $\mathrm{BABA}$ primes $\mathrm{H}_{2} \mathrm{O}_{2}$, which is a necessary event for callose callose accumulation following challenge. For this sequence of events, GSHI and RBOHD are essential genes, because both mutants (pad2 and rbohD, respectively) are impaired in callose and $\mathrm{H}_{2} \mathrm{O}_{2}$ priming as well as induced resistance. On the other hand, BABA can protect cat 2 and vtcl by priming camalexin; thus, CAT2 and VTCl are dispensable genes that contribute to priming of callose and $\mathrm{H}_{2} \mathrm{O}_{2}$ but not to induced resistance. 
while CAT2 and VTC1 are dispensable for BABA-IR (Fig. 8). BABA-induced expression of $R B O H D$ can directly contribute to augmented $\mathrm{H}_{2} \mathrm{O}_{2}$ accumulation after pathogen challenge but the role of GSHI is less obvious. It may contribute to a finetuning of the GSH/GSSG ratio after pathogen attack that leads to a reduced capacity to scavenge pathogen-inducible ROS, thereby allowing for a further increase of pathogen-induced ROS and augmented callose deposition.

\section{MATERIALS AND METHODS}

Plant material, growth conditions, and chemical treatments.

For in vitro assays, seed of Arabidopsis thaliana accession Col-0 and mutants in this background-rbohD (SALK 070610), pad2 (Parisy et al. 2007), cat2 (Bueso et al. 2007), vtc1 (Conklin et al. 2000), and pen2-2 (Lipka et al. 2005) were vapor-phase sterilized for 4 to $6 \mathrm{~h}$ (University of Wisconsin Department of Entomology, Madison, WI, U.S.A.. Approximately 15 sterilized seeds were sown per well in sterile 12well plates, each containing $1 \mathrm{ml}$ of sterilized basal MS medium without Gambor's vitamins (Duchefa, Haarlem, The Netherlands), with $1 \%$ sucrose. All growth media were supplemented with $0.5 \%$ morpholineethane-sulfonic acid hydrate (Sigma, St. Louis) with final pH of 5.7 to 5.8. Seedlings were cultivated under standard growth conditions (16-h-day and 8-hnight cycle, 20 and $17^{\circ} \mathrm{C}$, respectively) at $150 \mu \mathrm{M} \mathrm{m}^{-2} \mathrm{~s}^{-1}$. After 7 days of growth, MS medium was replaced by fresh MS medium. At day 8, BABA (Sigma) at $1 \mathrm{ppm}$ was applied as a final concentration. After $24 \mathrm{~h}$ of BABA treatment, seedlings were challenged by $1 \mu \mathrm{M}$ Flg22 (GenScript, Piscataway, NJ, U.S.A.) or $0.01 \%$ (wt/vol) low-viscous chitosan (Fluka, Milwaukee, WI, U.S.A.) as a final concentration which has a molecular weight of approximately $150 \mathrm{kDa}$ and a 95-to-99.8\% degree of acetylation (Hombach and BernkopSchnürch 2009). Mock treatments were performed by addition of sterilized, distilled water at the same volume as the PAMP treatments. At day 9, the samples were collected for analysis.

Experiments with adult plants were performed as follows: seed of Col-0 and mutants were sown in Jiffy-7 peat pellets (Clause-Tezier Ibérica, Valencia, Spain). Plants were grown in a growth phytochamber with 100 to $150 \mu \mathrm{M} \mathrm{m}^{-2} \mathrm{~s}^{-1}$ at 21 and $19^{\circ} \mathrm{C}$ under 9 -h light cycles and $65 \%$ humidity. Five-week-old plants were pretreated with $150 \mu \mathrm{M}$ BABA.

\section{Callose and $\mathrm{H}_{2} \mathrm{O}_{2}$ determination, microscopy analysis, and quantification.}

For in vitro staining experiments, aniline-blue and DAB were used to determine callose and $\mathrm{H}_{2} \mathrm{O}_{2}$ levels, as described by Luna and associates (2011). Both were quantified in micrographies using the GIMP (version 2.6.12) software, and the contrast in colors was obtained using the threshold color tool. In adult plants, leaves were sampled 3 days postinfection. For adult plants, callose staining in aniline-blue was performed as described by Ton and Mauch-Mani (2004). For DAB staining, leaves were cut and put immediately in DAB at $1 \mathrm{mg} / \mathrm{ml}$; subsequently, leaves were destained in $96 \%$ ethanol and rehydrated in glycerol $60 \%$. Callose was visualized by epifluorescence microscope with a UV filter and $\mathrm{H}_{2} \mathrm{O}_{2}$ by bright-field microscopy.

\section{P. cucumerina bioassays and culture.}

Five-week-old plants were soil drenched with water (control) or $150 \mu \mathrm{M}$ BABA as a final concentration, $48 \mathrm{~h}$ prior to infection. Then, plants were challenged by $6-\mu$ drops of $5 \times$ $10^{6}$ spores $\mathrm{ml}^{-1}$ to fully expanded leaves. Plants were maintained at $100 \%$ relative humidity. Disease symptoms were evaluated by determining the average of lesion diameter in 20 to 30 plants per treatment and time point, at 7 days after inoculation. These experiments were repeated at least three times with similar results.

\section{Quantitative real-time reverse-transcription polymerase chain reaction (RT-PCR) analysis of transcripts.}

Gene expression by quantitative real-time RT-PCR was performed using RNA samples extracted from leaf tissue using the E.Z.N.A. Plant RNA Kit (Omega Bio-Tek, Norcross, GA, U.S.A.). Arabidopsis leaf tissues samples for RNA isolation were collected at 0,48 , and $72 \mathrm{~h}$ after inoculation. Leaf tissues from eight plants were collected. For quantitative real-time PCR, $1.5 \mu \mathrm{g}$ of total RNA was digested, using $1 \mathrm{U}$ of RQ1 Rnase-Free Dnase buffer and up to $10 \mu \mathrm{l}$ of Milli-Q water, and was incubated for $30 \mathrm{~min}$ at $37^{\circ} \mathrm{C}$. After incubation, $1 \mu \mathrm{lof}$ RQ1 Dnase stop buffer was added, and the solution was incubated again at $65^{\circ} \mathrm{C}$ for $10 \mathrm{~min}$ to inactivate the Dnase. Highly pure RNA was used for the RT reaction. The RT reaction was performed by adding $2 \mu \mathrm{l}$ of RT buffer, $2 \mu \mathrm{l}$ of $5 \mathrm{mM} \mathrm{dNTP}$, $2 \mu \mathrm{l}$ of $10 \mu \mathrm{M}$ Oligo (dT) 15 primer (Promega Corp., Madison,

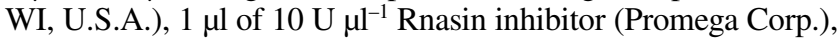
and $1 \mu \mathrm{l}$ of Omniscript reverse transcriptase (Qiagen, Hilden, Germany). The reaction mixture was incubated at $37^{\circ} \mathrm{C}$ for 60 min. Less than $10 \%$ of the volume of the RT reaction was used for the quantitative PCR. A melting curve analysis was performed at the end of the PCR reaction to confirm the product purity. The primers used in this study are included in table S1. Values are normalized with GAPDH3 expression in the same sample using the $2^{\Delta \mathrm{Ct}}$ method, where $\Delta \mathrm{Ct}=$ cycle threshold (Ct) (reference gene) - Ct (gene of interest). Fold-induction values of gene expression were normalized to values relative to Col-0 water or Col-0 BABA at $0 \mathrm{~h}$ before infection. The experiments were repeated with Atlg13320 with similar results.

\section{Determination of GSH, GSSG, and camalexin.}

GSH and GSSG were extracted and quantified as described by Rellán-Álvarez and associates (2006), with some modifications. Briefly, for quantification of both compounds, we used liquid chromatography (LC) electrospray ionization tandem mass spectrometry coupled to a triple quadrupole (TQD) Waters, Manchester, U.K.) in positive mode, using homoglutathion as an internal standard. The LC separation was performed using an Acquity UPLC BEH C18 analytical column, 1.7-mm particle size, $2.150 \mathrm{~mm}$ (Waters). Camalexin was extracted using an aqueous/MeOH (90:10) solution containing $0.01 \% \mathrm{HCOOH}$. The leaf material was gridded on ice and centrifuged at $16,000 \times g$ for $15 \mathrm{~min}$. The liquid extracts were analyzed by LC-mass spectrometry (TQD) (Waters). The LC separation was performed by high-performance liquid chromatography SunFire C18 analytical column, 5-um particle size, $2.1 \times 100 \mathrm{~mm}$ (Waters, Milford, MA, U.S.A.). Analytes were eluted with a gradient of methanol and water containing $0.01 \%$ $\mathrm{HCOOH}$. The identification and relative quantification was performed by comparing the mass spectrometry signals with a camalexin standard provided by U. Conrath (University of Aachen). The retention time for camalexin was $11.8 \mathrm{~min}$ and the transition in positive electrospray mode of the parental and daughter ions was 201.1 and 59.1 respectively.

\section{ACKNOWLEDGMENTS}

This work was financially supported by the project from the Plant de Promoción Univesitat Jaume I (P1.1B2010-06) and National R\&D Plan (AGL2010-22300-C03-01). We thank the SCIC at the Universitat Jaume I for its technical assistance and B. Mauch-Mani for critically revising the manuscript. 


\section{LITERATURE CITED}

Apel, K., and Hirt, H. 2004. Reactive oxygen species: Metabolism, oxidative stress, and signal transduction. Annu. Rev. Biol. 55:373-399.

Arrigoni, O., and De Tullio, M.C. 2002. Ascorbic acid: Much more than just an antioxidant. Biochim. Biophys. Acta 1569:1-9.

Beckers, G. J. M., Jaskiewicz, M., Liu, Y., Underwood, W. R., He, S. Y., Zhang, S., and Conrath, U. 2009. Mitogen-activated protein kinases 3 and 6 are required for full priming of stress responses in Arabidopsis thaliana. Plant Cell 21:944-953.

Bent, A., and Mackey, D. 2007. Elicitors, effectors, and $R$ genes: The new paradigm and a lifetime supply of questions. Annu. Rev. Phytopathol. 45:399-436.

Boller, T., and Felix, G. 2009. A renaissance of elicitors: Perception of microbe-associated molecular patterns and danger signals by patternrecognition receptors. Annu. Rev. Plant Biol. 60:379-406.

Bueso, E., Alejandro, S., Carbonell, P., Perez-Amador, M. A., Fayos, J., Bellés, J. M., Rodríguez, P. L., and Serrano, R. 2007. The lithium tolerance of the Arabidopsis cat 2 mutant reveals a cross-talk between oxidative stress and ethylene. Plant J. 52:1052-1065.

Camañes, G., Pastor, V., Cerezo, M., García-Andrade, J., Vicedo, B., GarcíaAgustín, P., and Flors, V. 2012. A deletion in NRT2.1 Attenutes Pseudomonas syringae-induced hormonal perturbation, resulting in primed plant defences. Plant Physiol. 158:1054-1066.

Clay, N. K., Adio, A. M., Denoux, C., Jander, G., and Ausubel, F. M. 2009. Glucosinolate metabolites required for an Arabidopsis innate immune response. Science 323:95-101.

Conklin, P. L., and Barth, C. 2004. Ascorbic acid, a familiar small molecule intertwined in the response of plants to ozone, pathogens, and the onset of senescence. Plant Cell Environ. 27:959-970.

Conklin, P. L., Saracco, S. A., Norris, S. R., and Last, R. L. 2000. Identification of ascorbic acid-deficient Arabidopsis thaliana mutants. Genetics 154:847-856.

Conrath, U. 2011. Molecular aspects of defence priming. Trends Plant Sci. 16:524-531.

Conrath, U., Thulke, O., Katz, V., Schwindling, S., and Kohler, A. 2001. Priming as mechanism in induced systemic resistance of plants. Eur. J. Plant Pathol. 107:113-119.

D'Autréaux, B., and Toledano, M. B. 2007. ROS as signalling molecules: Mechanisms that generate specificity in ROS homeostasis. Mol. Cell Biol. 8:813-824.

Davletova, S., Rizhsky, L., Liang, H., Shengqiang, Z., Oliver, D. J., Coutu, J., Shulaev, V., Schlauch, K., and Mittler, R. 2005. Cytosolic Ascorbate Peroxidase 1 is a central component of the reactive oxygen gene network in Arabidopsis. Plant Cell 17:268-281.

de Pinto, M. C., Paradiso, A., Leonetti, P., and De Gara, L. 2006. Hydrogen peroxide, nitric oxide and cytosolic ascorbate peroxidase at the crossroad between defence and cell death. Plant J. 48:784-795.

Desikan, R., Horák, J., Chaban, C., Mira-Rodado, V., Witthöft, J., Elgass, K., Grefen, C., Cheung, M. K., Meixner, A. J., Hoolev, R., Neill, S. J., Hancok, J. T., and Harter, K. 2008. The histidine kinase AHK5 integrates endogenous and environmental signals in Arabidopsis guard cells. PLoS One 3:e2491. doi:10.1371/journal.pone.0002491. Published online.

Dubreuil-Maurizi, C., Trouvelot, S., Frettinger, P., Pugin, A., Wendehenne, D., and Poinssot, B. 2010. $\beta$-Aminobutyric acid primes and NADPH oxidase-dependent reactive oxygen species production during grapevine-triggered immunity. Mol. Plant-Microbe Interact. 23:1012-1021.

Dubreuil-Maurizi, C., Vitecek, J., Marty, L., Branciard, L., Frettinger, P., Wendehenne, D., Meyer, A. J., Mauch, F., and Poinssot, B. 2011. Glutathione deficiency of the Arabidopsis mutants pad2-1 affects oxidative stress-related events, defence gene expression, and the hypersensitive response. Plant Physiol. 157:2000-2012.

Felix, G., Duran, J. D., Volko, S., and Boller, T. 1999. Plants have a sensitive perception system for the most conserved domain of bacterial flagellin. Plant J. 18:265-276.

Flors, V., Ton, J., van Doorn, R., Jakab, G., García-Agustín, P., and Mauch-Mani, B. 2008. Interplay between JA, SA, and ABA signalling during basal and induced resistance against Pseudomonas syringae and Alternaria brassicicola. Plant J. 54:81-92.

Foyer, C. H., and Noctor, G. 2005a. Redox homeostasis and antioxidant signalling: A metabolic interface between stress perception and physiological responses. Plant Cell 17:1866-1875.

Foyer, C. H., and Noctor, G. 2005b. Oxidant and antioxidant signalling in plants: A re-evaluation of the concept of oxidative stress in a physiological context. Plant Cell Environ. 28:1056-1071.

Friedrich, L., Lawton, K., Ruess, W., Masner, P., Specker, N., Gut Rella, M., Meier, B., Dincher, S., Staub, T., Ukness, S., Métraux, J. P., Kessmann, H., and Ryals, J. 2003. A benzothiadiazole derivative induces systemic acquired resistance in tobacco. Plant J. 10:31-70.
Gadjev, I., Vanderauwera, S., Gechev, T. S., Laloi, C., Minkov, I. N., Shulaev, V., Apel, K., Inzé, D., Mittler, R., and Breusegem, F. V. 2006. Transcriptomic footprints disclose specificity of reactive oxygen species signalling in Arabidopsis. Plant Physiol. 141:436-445.

Galletti, R., Denoux, C., Gambetta, S., Dewdney, J., Ausubel, F. M., DeLorenzo, G., and Ferrari, S. 2008. The AtrbohD-mediated oxidative burst elicited by oligogalacturonides in Arabidopsis is dispensable for the activation of defence responses effective against Botrytis cinerea. Plant Physiol. 148:1695-1706.

García-Andrade J., Ramírez V., Flors V., and Vera P., 2012. Arabidopsis ocp3 mutant reveals a mechanism linking $\mathrm{ABA}$ and JA to pathogeninduced callose deposition. Plant J. 67:783-794.

Gechev, T. S., and Hille, J. 2005. Hydrogen peroxide as a signal controlling plant programmed cell death. J. Cell Biol. 168:17-20.

Ghanta, S., and Chattopadhyay, S. 2011. Glutathione as a signalling molecule. Another challenge to pathogens. Plant Signal. Behav. 6:783-788.

Ghanta, S., Bhattacharyya, D., Sinha, R., Banerjee, A., and Chattopadahyay, S. 2011. Nicotiana tabacum overexpressing gamma-ECS exhibits biotic stress tolerance likely through NPR1-dependent salicylic acid mediated pathway. Planta 233:895-910.

Gomez-Gomez, L., and Boller T. 2000. FLS2: An LRR receptor-like kinase involved in the perception of the bacterial elicitor flagellin in Arabidopsis. Mol. Cell 5:1003-1012.

Gomez-Gomez, L., Felix, G., and Boller, T. 1999, A single locus determines sensitivity to bacterial flagellin in Arabidopsis thaliana. Plant $\mathrm{J}$. 18:277-284.

Ham, J. H., Kim, M. G., Lee, S. Y., and Mackey, D. 2007. Layered basal defenses underlie non-host resistance of Arabidopsis to Pseudomonas syringae pv. phaseolicola. Plant J. 51:604-616.

Hancock, J., Desikan, R., Harrison, J., Bright, J., Hooley, R., and Neill, S. 2006. Doing the unexpected: Proteins involved in hydrogen peroxide perception. J. Exp. Bot. 57:1711-1718.

Hombach, J., and Bernkop-Schnürch, A. 2009. Chitosan solutions and particles: Evaluation of their permeation enhancing potential on MDCK cells used as a blood brain barrier model. Int. J. Pharm. 376:104-109.

Iritri, M., and Faoro, F. 2009. Chitosan as a MAMP, searching for a PRR. Plant Signal. Behav. 4:66-68.

Jakab, G., Cottier, V., Toquin, V., Rigoli, G., Zimmerli, L., Metraux, J. P., and Mauch-Mani, B. 2001. Beta-aminobutyric acid-induced resistance in plants. Eur. J. Plant Pathol. 107:29-37.

Jakab, G., Ton, J., Flors, V., Zimmerli, L., Metraux, J., and Mauch-Mani, B. 2005. Enhancing Arabidopsis salt and drought stress tolerance by chemical priming for its abscisic acid responses. Plant Physiol. 139:267-274.

Jaskiewicz, M., Conrath, U., and Peterhänsel, C. 2011. Chromatin modification acts as a memory for systemic acquired resistance in the plant stress response. EMBO (Eur. Mol. Biol. Organ.) Rep. 12:50-55.

Jonak, C., Okrész, L., Bögre, L., and Hirt, H. 2002. Complexity, cross-talk and integration of plant MAP kinase signaling. Curr. Opin. Plant Biol. 5:415-424.

Jones, J. D. G., and Dangl, J. L. 2006. The plant immune system. Nature 444:323-329.

Jung, H. W., Tschaplinski, T. J., Wang, L., Glazebrook, J., and Greenberg, J. T. 2009. Priming in systemic plant immunity. Science 234:89-91.

Kessmann, H., Staub, T., Hofmann, C., Maetzke, T., Herzog, J., Ward, E., Uknes, S., and Ryals, J. 1994. Induction of systemic acquired resistance in plants by chemicals. Annu. Rev. Phytopathol. 32:439-459.

Laloi, C., Apel, K., and Danon, A. 2004. Reactive oxygen signalling: The latest news. Curr. Opin. Plant Biol. 7:323-328.

Laloi, C., Stachowiak, M., Pers-Kamczyc, E., Warzy E., Murgia I., and Apel, K. 2007. Cross-talk between singlet oxygen- and hydrogen peroxide-dependent signalling of stress responses in Arabidopsis thaliana. Proc. Natl. Acad. Sci. U.S.A. 104:672-677.

Lamb, C., and Dixon, R. A. 1997. The oxidative burst in plant disease resistance. Annu. Rev. Plant Physiol. Plant Mol. Biol. 48:251-275.

Lipka, V., Dittgen, J., Bednarek, P., Bhat, R., Wiermer, M., Stein, M., Landtag, J., Brandt, W., Rosahl, S., Scheel, D., Llorente, F., Molina, A., Parker, J., Somerville, S., and Schulze-Lefert, P. 2005. Pre- and postinvasion defences both contribute to nonhost resistance in Arabidopsis. Science 310:1180-1183.

Luna, E., Pastor, V., Robert, J., Flors, V., Mauch-Mani, B., and Ton, J. 2011. Callose deposition: A multifaceted plant defence response. Mol. Plant-Microbe Interact. 24:183-193.

Luna, E., Bruce, T. J. A., Roberts, M. R., Flors, V, and Ton, J. 2012. Next generation systemic acquired resistance. Plant Physiol. 158:844-853.

Meng, L., Wong, J. H., Feldman, L. J., Lemaux, P. G., and Buchanan, B. B. 2010. A membrane-associated thioredoxin required for plant growth moves from cell to cell, suggestive of a role in intercellular communication. Proc. Natl. Acad. Sci. U.S.A. 107:3900-3905.

Miller, G., Suzuki, N., Rizhsky, L., Hegie, A., Koussevitzky, S., and Mittler, 
R. 2007. Double mutants deficient in cytosolic and thylakoid ascorbate peroxidase reveal a complex mode of interaction between reactive oxygen species, plant development, and response to abiotic stress. Plant Physiol. 144:1777-1785.

Miller, G., Schlauch, K., Tam, R., Cortes, D., Torres, M. A., Shulaev, V., Dangl, J. L., and Mittler, R. 2009. The plant NADPH oxidase RBOHD mediates rapid systemic signalling in response to diverse stimuli. Sci. Signal. 2:ra45.

Mittler, R., Vanderauwera, S., Suzuki, N., Miller, G., Tognetti, V.B., Vandepoele, K., Gollery, M., Shulaev, V., and Van Breusegem, F. 2011. ROS signalling: The new wave?. Trends Plant Sci. 16:300-309.

Mou, Z., Fan, W., and Dong, X. 2003. Inducers of plant systemic acquired resistance regulate NPR1 function through redox changes. Cell 113:935-944.

Neill, S., Desikan, R., and Hancock, J. 2002. Hydrogen peroxide signalling. Curr. Opin. Plant Biol. 5:388-395.

Noctor, G. 2006. Metabolic signalling in defence and stress: The central roles of soluble redox couples. Plant Cell Environ. 29:409-425.

Noctor, G., Mhamdi, A., Chaouch, S., Han, Y., Neukermans, J., Queval, G., and Foyer, C. H. 2012. Glutathione in plants: An integrated overview. plant cell environ. 35:454-484.

Parisy, V., Poinssot, B., Owsianowski, L., Buchala, A., Glazebrook, J., and Mauch, F. 2007. Identification of PAD2 as a gamma-glutamylcysteine synthetase highlights the importance of glutathion in disease resistance of Arabidopsis. Plant J. 49:159-172.

Pastor, V., Luna, E., Mauch-Mani, B., Ton, J., and Flors, V. 2013. Primed plants do not forget. Environ. Exp. Bot. 94:46-56.

Pastori, G. M., Kiddle, G., Antoniw, J., Bernard, S., Veljovic-Jovanovic, S., Verrier, P. J., Noctor, G., and Foyer, C. H. 2003. Leaf vitamin C contents modulate plant defence transcripts and regulate genes that control development through hormone signalling. Plant Cell 15:939-951.

Pei, Z. M., Murata, Y., Benning, G., Thomine, S., Klüsener, B., Allen, G. J., Grill, E., and Schroeder, J. I. 2000. Calcium channels activated by hydrogen peroxide mediate abscisic acid signalling in guard cells. Nature 406:731-734.

Pógany, M, von Rad, U, Grun, S, Dongo, A, and Pintye, A. 2009. Dual Roles of reactive oxygen species and NADPH oxidase RBOHD in an Arabidopsis-Alternaria pathosystem. Plant Physiol. 151:1459-1475.

Po-Wen, C., Singh, P., and Zimmerli, L. 2013. Priming of the Arabidopsis pattern-triggered immunity response upon infection by necrotrophic Pectobacterium carotovorum bacteria. Mol. Plant Pathol. 14:58-70.

Pozo, M. J., Van Der Ent, S., Van Loon, L. C., and Pieterse, C. M. J. 2008. Transcription factor MYC2 is involved in priming for enhanced defence during rhizobacteria-induced systemic resistance in Arabidopsis thaliana RID A-9326-2011. New Phytol. 180:511-523.

Queval, G., Jaillard, D., Zechmann, B., and Noctor, G. 2011. Increased intracellular $\mathrm{H}_{2} \mathrm{O}_{2}$ availability preferentially drives glutathione accumulation in vacuoles and chloroplast. Plant Cell Environ. 34:21-32.

Rasmann, S., De Vos, M., Casteel, C. L., Tian, D., Halitschke, R., Sun, J. Y., Agrawal, A. A., Felton, G. W., and Jander. G. 2012. Herbivory in the previous generation primes Arabidopsis and tomato for enhanced insect resistance. Plant Physiol. 158:854-863.

Rellán-Álvarez, R., Hernández, L. E., Abadia, J., and Alvarez-Fernández,
A. 2006. Direct and simultaneous determination of reduced and oxidized glutathione and homoglutathione by liquid chromatography-electrospray/mass spectrometry in plant tissue extracts. Anal. Biochem. 356:254-264.

Sagi, M., and Fluhr, R. 2006. Production of reactive oxygen species by plant NADPH oxidases. Plant Physiol. 141:336-340.

Schlaeppi, K., Abou-Mansour, E., Buchala, A., and Mauch, F. 2010, Disease resistance of Arabidopsis to Phytophthora brassicae is established by the sequential action of indole glucosinolates and camalexin. Plant J. 62:840-851.

Singh, P., Kuo, Y., Mishra, S., Tsai, C., Chien, C., Chen, C., DesclosTheveniau, M., Chu, P., Schulze, B., Chinchilla, D., Boller, T., and Zimmerli, L. 2012. The lectin receptor kinase-VI.2 is required for priming and positively regulates Arabidopsis pattern-triggered immunity. Plant Cell 24:1256-1270.

Slaughter, A., Daniel, X., Flors, V., Luna, E., Hohn, E., and Mauch-Mani, B. 2012. Descendants of primed Arabidopsis plants exhibit resistance to biotic stress. Plant Physiol. 158:835-843.

Spoel, S. H., and Loake, G. J. 2011. Redox-based protein modifications: The missing link in plant immune signalling. Curr. Opin. Plant Biol.14:358-364.

Spoel, S. H., Tada, Y., and Loake, G. J. 2010. Post-translational protein modification as a tool for transcription reprogramming. New Phytol. 186:333-339

Tada, Y., Spoel, S. H., Pajerowska-Mukhtar, K., Mou, Z, Song, J., Wang, C., Zuo, J., and Dong, X. 2008. Plant immunity requires conformational charges of NPR1 via S-nitrosylation and thioredoxins. Science 321:952-956.

Ton, J., and Mauch-Mani, B. 2004. Beta-amino-butyric acid-induced resistance against necrotrophic pathogens is based on ABA-dependent priming for callose. Plant J. 38:119-130.

Ton, J., Jakab, G., Toquin, V., Flors, V., Iavicoli, A., Maeder, M. N., Metraux, J. P., and Mauch-Mani, B. 2005. Dissecting the beta-aminobutyric acid-induced priming phenomenon in Arabidopsis. Plant Cell 17:987-999.

Tsuda, K., and Katagiri, F. 2010. Comparing signalling mechanisms engaged in pattern-triggered and effector-triggered immunity. Curr. Opin. Plant Biol. 13:459-465.

van der Ent, S., Van Hulten, M., Pozo, M. J., Czechowski, T., Udvardi, M. K., Pieterse, C. M. J., and Ton, J. 2009. Priming of plant innate immunity by rhizobacteria and beta-aminobutyric acid: Differences and similarities in regulation. New Phytol. 183:419-431.

van Hulten, M., Pelser, M., van Loon, L., Pieterse, C., and Ton, J. 2006. Costs and benefits of priming for defence in Arabidopsis. Proc. Natl. Acad. Sci. U. S. A. 103:5602-5607.

Wojtaszek, P. 1997. Oxidative burst: An early plant response to pathogen infection. Biochem. J. 332:681-692.

Zimmerli, L., Jakab, G., Métraux, J.-P., and Mauch-Mani, B. 2000. Potentiation of pathogen-specific defence mechanisms in Arabidopsis by b-aminobutyric acid. Proc. Natl. Acad. Sci. U.S.A. 97:1292012925.

Zipfel, C. 2009. Early molecular events in PAMP-triggered immunity. Curr. Opin. Plant Biol. 12:414-420. 